\title{
Levers Of Control: Analysis Of Management Control Systems In A Slovenian Company
}

\author{
Metka Tekavčič, University of Ljubljana, Slovenia \\ Darja Peljhan, University of Ljubljana, Slovenia \\ Željko Šević, University of Greenwich, UK
}

\begin{abstract}
In the paper, we study management control from the Simons' four levers of control framework point of view (i.e. diagnostic control systems, interactive control systems, beliefs systems, and boundary systems). The theoretical framework is tested by the use of an in-depth case study. We investigate how are MCS deployed by a case company according to Simons' four levers of control and how does a company use them. The paper looks at tensions and balances between different styles of use of formal MCS, as well as between different types of control systems (e.g. formal vs. informal). The study's contribution is that it incorporates a wider range of controls, including informal (i.e. social) mechanisms, to provide a more comprehensive analysis, as opposed to the majority of prior studies focusing on a more limited range of controls.
\end{abstract}

Key words: beliefs systems, boundary systems, case study, diagnostic control systems, interactive control systems, levers of control, management control, management control systems

\section{INTRODUCTION}

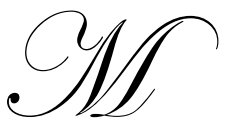

anagement control systems (MCS) have attracted growing attention in the practical and theoretical spheres in recent years. They are systems for influencing human endeavor within the company (Flamholtz et al. 1985; Langfield-Smith 1997). For the purposes of this paper, management control system is defined broadly as a system conveying useful information to assist managers in their jobs and decision-making to efficiently and effectively achieve desired organizational goals (see also: Anthony \& Govindarajan 2001; Langfield-Smith 1997; Otley 1999). The definition of MCS in this paper embraces both formal and informal information-based routines and procedures for being able to investigate the "control package" (Otley, 1980, 1999) in its entirety. As a result, MCS involve both personal (Merchant 1985), clan control (Ouchi 1980) and performance measurement systems in general, combining both financial and non-financial information ${ }^{1}$. In this work, MCS are not defined by their technical design features. They are defined by how managers use these systems for decision-making in the process of organizational performance management.

In this paper, management control is studied from the Simons' (1995a, 1995b, 2000) four levers of control framework point of view (see: Figure 1 in section 2). The four levers of control consist of: diagnostic control systems; interactive control systems; beliefs systems and boundary systems. The Simons' (1995b) levers of control framework combine a focus on strategy with a wider view of the control mechanisms that can be utilized to implement strategy. Control of business strategy is achieved by integrating these four levers of control. The power of these levers in implementing strategy does not lie in how each is used individually, but rather in how they complement each other when used together. These four levers create tension between creative innovation and

\footnotetext{
${ }^{1}$ For more on the importance of financial and non-financial information in strategy development and implementation see Bhimani \& Langfield-Smith, 2007.
} 
predictable goal movement. This tension requires managers of effective companies to know how to achieve both high degrees of learning (innovation) and high degrees of control (efficiency) (Simons 2000).

The theoretical framework is tested by the use of an in-depth explanatory case study method to answer the following research question "How are MCS deployed by a case company according to Simons' (1995a) four levers of control and how does a company use them?" Our empirical research involves a longitudinal element and studies the operation of a set of control systems over a period of time, enabling the inter-relationship between different control systems elements to be examined and explained. In this way, both the antecedents and consequences of control systems choices can be explored. When selecting a company for this study, the goal was not to document average practice but rather, to learn about innovative, leading-edge best practice. The case study company is a large Slovenian manufacturing company - Trimo Trebnje, d.d. (hereafter Trimo) investigated during the period $1992-$ 2004. Trimo, for many years, has been the leading Slovenian company for the production and assembly of prefabricated steel constructions and one of the most important European manufacturers of pre-fabricated buildings and containers. It is a Slovenia-based company which has achieved its business vision of becoming the leading European company offering complete solutions in the area of steel buildings.

The paper is organized as follows. A literature review on levers of control framework is provided in section 2. Section 3 is methodological, introducing the case study research methods that we used in the study. Research results are presented in section 4 . Further discussion and interpretation of the research results follow in section 5. In section 6 we provide our final conclusions.

\section{LEVERS OF CONTROL FRAMEWORK}

Simons $(1987,1990,1991,1994)$ presented a series of cases that contribute to a theory of how senior managers can use controls to implement and develop strategy, which culminated in his book 'Levers of Control' (Simons 1995b), where he has outlined how management controls can contribute to effective strategy implementation. Simons argued that it is not the identification of controls associated with particular strategies that are important, but the distribution of management attention among controls. He introduced four key constructs that have to be analyzed and understood in order to implement strategy successfully: core values; risks to be avoided; critical performance variables and strategic uncertainties. Each construct is controlled by a different system, or lever, the use of which has different implications. These levers are (Simons 1995a):

- $\quad$ Beliefs systems used to inspire and direct the search for new opportunities.

- $\quad$ Boundary systems used to set limits on opportunity-seeking behavior.

- Diagnostic control systems used to motivate, monitor and reward achievement of specified goals.

- Interactive control systems used to stimulate search and learning, allowing new strategies to emerge as participants throughout the organization respond to perceived opportunities and threats. As a fourth lever of control, these systems focus attention on strategic uncertainties and enable strategic renewal.

Simons (1995b) organizes MCS tools into a coherent model called "levers of control". Four levers of control are graphically depicted in Figure 1. Control of the strategy is achieved by integrating these four levers of control.

Diagnostic control systems are formal information systems that managers use to monitor organisational outcomes and correct deviations from pre-set standards of performance (Simons 1995b). Managers are interested primarily in monitoring diagnostic control systems that report variance information about critical performance variables - those factors that have to be achieved or implemented successfully for the intended strategy of the business to succeed. One of the main purposes of diagnostic systems is to eliminate a manager's burden of constant monitoring. Instead of constantly monitoring a variety of internal processes and comparing results with preset targets and goals, managers receive periodic exception reports from different staff groups (e.g. analysts, accountants). 
Figure 1: Four Levers of Control

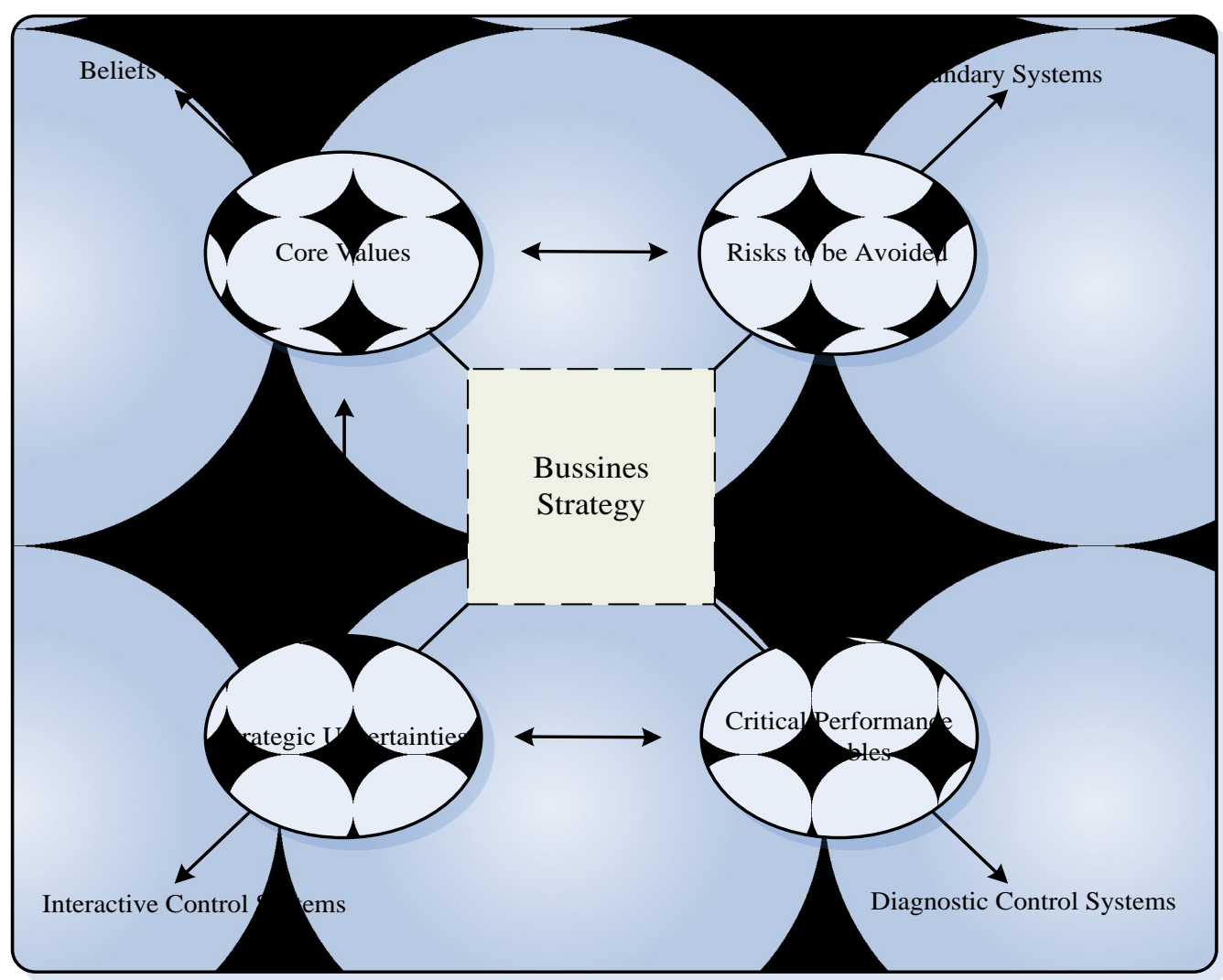

Source: Simons 1995a.

Interactive control systems are the formal information systems that managers use to involve themselves regularly and personally in the decisions of subordinates. Through them, senior managers participate in the decisions of subordinates and focus organizational attention and learning on key strategic issues. Any medium- to large-size business has a multitude of formal performance measurement and control systems - profit planning and budgeting systems, cost accounting, balanced scorecards, project monitoring systems and so on. Most of these systems are used diagnostically. The difference between diagnostic and interactive control systems is not in their technical design features, but in the way managers use these systems. Only top managers can decide which control systems they desire to use interactively, based on their vision of the future for the business and their personal sense of strategic uncertainties. The objective is to keep the interactive system simple, so that paperwork and forms do not become more important than face-to-face dialogue and action planning.

Interactive control systems are measurement systems that are used to focus attention on the constantly changing information that top-level managers consider to be of strategic importance. In contrast to diagnostic controls, what characterizes interactive controls is senior managers' strong level of involvement. Top managers pay frequent and regular attention to interactive control systems and become personally involved in them. Furthermore, this pattern of attention signals the need for organizational members to pay frequent and regular attention to the issues addressed by the interactive control systems. Through interactive control systems, top managers send messages to the entire organization in order to focus attention on strategic uncertainties. Consequently, interactive control systems put pressure on operating managers at all levels of the organization and motivate information gathering, face-to-face dialogue and debate. As participants throughout the organization respond to the perceived opportunities and threats, organizational learning is stimulated, new ideas flow and strategies emerge. In this way, interactive control systems guide and provide input to innovation and to the formation of emergent strategies. 
Diagnostic control systems and interactive control systems work together to allow the implementation of today's strategy, while at the same time allowing the company to position itself for tomorrow's changing marketplace. For example, it is interesting to note how Kaplan and Norton (2001) point out the importance of using the Balanced Scorecard (BSC) as an interactive control system. It is clear that a company has to have some experience with other control systems before it can exploit the BSC in this way. Kaplan and Norton (2001) argue that diagnostic systems, boundary systems and internal control systems are all necessary, but they do not create a learning organization aligned to a focused strategy. Some BSC implementation failures occurred because organizations used their scorecard only diagnostically and failed to get the learning and innovation benefits from an interactive system. Managing Directors of successful BSC adopters succeeded because they used the scorecard interactively, for communication and to drive learning and improvement. They set the overall strategy and then encouraged people within their organization to identify the local actions and initiatives that would have the highest impact for accomplishing the scorecard objectives.

Besides diagnostic and interactive control systems, there are also beliefs and boundary systems. Simons (1995b) argues that companies have used beliefs systems for years in an effort to articulate the values and direction that senior managers want their employees to embrace. Top-level managers rely increasingly on empowered employees to generate new ideas to achieve competitive advantage. Therefore, participants from all parts of an organization need to understand, as clearly as possible, the company's purposes and mission (Simons 1995a). The statements achieve their ends only if employees believe, by watching the actions of senior managers, that the company's stated beliefs represent deeply rooted values. Indeed, some managers do not adopt missions and credos out of any real commitment, but because they seem fashionable. However, managers who use their missions as living documents - as part of a system to guide patterns of acceptable behavior - have discovered a powerful lever of control. Effective managers seek to inspire people throughout their organizations by actively communicating core values and missions.

The boundaries in modern organizations are embedded in standards of ethical behavior and codes of conduct. Human beings are inventive and, when presented with new opportunities or challenging situations, they often search for ways to create value or overcome obstacles. But empowerment, fuelled by inspiration and performance rewards, should never be interpreted as giving subordinates a blank cheque to do whatever they please. People generally want to do the right thing and to act ethically in accordance with established moral codes. However, pressures to achieve superior results sometimes clash with stricter codes of behavior. Because of temptation or pressure in the workplace, individuals sometimes choose to bend the rules. Not all boundaries concern standards of ethical conduct. Strategic boundaries, for example, focus on ensuring that people steer clear of opportunities that could diminish a business' competitive position (Simons 1995a). Working together, boundary systems and beliefs systems result in a dynamic tension between commitment and punishment. Together these systems establish direction, motivate and inspire, and protect against potentially damaging opportunistic behavior.

The levers of control are capable of reconciling the tensions between innovation and efficiency. Boundary systems are weighted heavily to controls and limits. However, they also reflect learning, because competitors' past mistakes and tactical moves dictate the adjusting business conduct and strategic boundaries. Diagnostic control systems clearly emphasize control and efficiency. On the other hand, setting goals, measuring outcomes, remedying variances and assigning rewards, involve elements of innovation and learning. Interactive control systems also involve both control and learning, although learning and innovation dominate, as senior managers use the interactive control process as a catalyst to force the organization to monitor changing market dynamics and motivate debate about data, assumptions and action plans. Over time, the information and learning generated by interactive control systems can be embedded in the strategies and goals that are monitored by diagnostic control systems (Simons 2000).

\section{METHODOLOGY}

To analyze management control systems in a Slovenian company, we have followed a case study methodology (Eisenhardt 1989; Yin 2003). Theory states that the strength of this method is the likelihood of it resulting in a new or upgraded theory (Eisenhardt 1989). Also, other scholars (Chenhall 2003; Ittner \& Larcker, 
2002; Otley 2001) argue that intensive, field-based methods are much more likely to pick up on the wide variety of control mechanisms deployed by organizations in practice and to ground theoretical development firmly in empirically observed practice. Therefore, the in-depth explanatory case study method enables the generation of exhaustive data on the use of MCS to yield much more insightful theories to be the basis for the learning of other companies. When undertaking the case study, multiple sources of evidence were used, establishing a chain of evidence. Data was gathered from formal and semi-formal interviews and observations during site visits and through the participation in Trimo's strategic conferences, from the study of internal and external documents, and from professional literature. This enabled us a systematic and comprehensive analysis.

Data on Trimo's management control systems were collected from various sources, including interviews with top and middle managers, company documents, and archival records. The use of multiple sources of evidence enabled verification through triangulation, which is the strength of case research (Noda \& Bower, 1996). A major concern of the present study was to triangulate managers' views and opinions with 'harder' evidence, such as that obtained from documents and archival records. An interview protocol ensured that the same themes were covered with each interviewee. Construct validity of the interview data was pursued through an 'action-research' approach. Eden and Huxham (2002) have argued that an action research setting increases the possibility of being able to access respondents 'theory-in-use', which in itself aids validity in this type of research. The questionnaire used and the semi-structured interviews were carefully constructed and contained questions to elicit information required to investigate research questions and as such it is assumed that construct validity is high. To avoid possible misunderstandings, respondents (top managers) were provided with descriptions of four levers of control from Simons' (1995b) definitions, translated into Slovene. A particular control system was deemed to exert a particular influence only if this effect could be traced to at least three-quarters of respondents. Interview data were continually cross-referenced with other data sources and cross-checked with the chronology of activities and events that took place during the course of the study. This form of triangulation enhanced the internal validity and reliability of the case study material. Finally, a draft research report was prepared and sent to all interviewees for comment. These were evaluated in order to ensure that reported ideas and propositions aligned with managers' experiences. This increased the construct validity of our research ( $c f$. Atkinson \& Shaffir 1998; Yin 2003).

\section{RESULTS}

Trimo's history began in 1961 when the company "Kovinsko podjetje Trebnje" was founded as a sociallyowned enterprise. The next year saw the beginning of another new company - "Kovinooprema". In 1971, both companies and some other smaller companies merged to form "Trimo Trebnje". The main activity of the new company was the production of metal elements and equipment made from stainless steel. In the following years, the former Yugoslavia and third world countries had many infrastructure and other projects, creating a high demand for Trimo's products. The 1980s, however, brought about crises in the export markets and the company faced its first major challenge. It responded with the modernization of its production line and the introduction of new fireproof products. ${ }^{2}$ For a short time it seemed that the company had overcome its problems, but in 1991 Slovenia became independent and the former multi-ethnic state of Yugoslavia fell apart. As Trimo lost the majority of its domestic (former federal) market, it had to suddenly re-orientate towards more competitive foreign markets, especially in the European Union and the emerging Central and Eastern European markets (see: Šević 2005).

As Trimo encountered many problems at the beginning of the 1990s, a true company turnaround was required and that also meant the need for a new vision and different approach to developing and implementing a business strategy. The major turnaround of the company was achieved in 1992 when new top management was appointed. During the period from 1992 to 2004, revenues and value added per employee grew seven times, export grew eight times and the number of employees decreased by 21 per cent (Trimo 2005b). Today, Trimo is a jointstock company with $€ 34,000$ value added per employee, internationally-oriented with 70 per cent of exports, mainly in Europe, operating in 40 countries. Their main products include pre-fabricated steel buildings, steel structures, façades, roofs, containers, and sound-isolating systems. Trimo's pre-fabricated steel buildings represent endless

\footnotetext{
${ }^{2}$ Before modernisation, Trimo used polyurethane as the filling for the building panels. After modernisation, they have used environmentally friendlier fireproof mineral wool that enables them to penetrate to more demanding markets.
} 
possibilities for use since they are suitable for office buildings, commercial buildings, sports facilities, warehouse facilities, industrial and other facilities (see: http://www.trimo.si/ 2005). Trimo's main product is called "complete solutions" and includes a mix of all the products and services Trimo is offering, from an idea and draft to the finished building. When looking into Trimo's production program, there is no similar company in Slovenia. Trimo is the market leader in the area of roofs and façades from mineral wool panels in west and central Europe and in the area of steel constructions in Slovenia (Kranjec 2003). With its business orientation towards offering complete solutions and with a broad production program, Trimo cannot be directly compared to any of its competitors who are all manufacturers with relatively focused production programs (Trimo 2005e). Trimo builds its strategy of long-term growth of the company on internationalization (Trimo 2004a).

Within Trimo, there exists a multitude of MCS, both formal and informal. Every one of these systems influences behavior be it intentionally or unintentionally. It is essential therefore that there is coherence between the systems and that employees receive a consistent message throughout the company and through time. The following subsections look into Trimo's four levers of control in more detail. Hence, the research question "How are MCS deployed by a case company according to Simons' (1995a) four levers of control and how does a company use them?" is answered.

\subsection{Diagnostic Control Systems}

Diagnostic control systems comprise the administrative controls which operate throughout a company. Examples of administrative controls in Trimo include accounting controls, budgets, all formal communicational procedures and internal audits based on certificates ISO 9001, ISO 14001 and OHSAS 18001. Clearly and exactly defined goals, as well as timely and accurate information on the actual goal accomplishment, play a key role in Trimo's performance management. Originally (i.e. before 2002) the diagnostic system was developed around the Oracle database, but as the existence of targets (i.e. standards) against which actual performance could be measured were not comprehensive, the ability to correct deviations from targets was not always possible. Therefore, they implemented BSC that includes elements of a diagnostic control system in the parts where it relies on the measurement and review of the past performance. The Managing Director commented: "With BSC we have better reviews, especially of key performance indicators." (Trimo 2005h). By using BSC, they can take immediate correctional actions in all the processes where there are negative deviations from pre-set plans. BSC is a good basis for employee incentives and motivation. At the moment, they are in the process of updating the incentives system that will be based even more on BSC.

Diagnostic control systems in Trimo exist according to the definitions of Simons (1995b). During the researched period (1992-2004), they were continuously updated. Performance reports (e.g. income statements) exist, as do detailed and complex reports on budget deviations. Sales deviations are portrayed and explanations provided. Margin overviews are provided. The problem is that reports are not always systematically acted upon and incorporated into top management decision-making, as not all of top management consistently use BSC. Rather, they rely on parallel information from databases that were used before BSC was introduced. The great opportunity in this area is a new ERP system implementation that has already begun. It will provide real time information on key performance indicators (KPIs).

Variance analyses are also conducted in the reports, focusing on discrepancies between actual and planned, and last year's performance, on the individual elements. The role of this review is also to find the employees responsible when variations occur so that they can be asked to explain. Reports also contain non-financial performance measures, for example customer satisfaction and different quality measures. As regards non-financial measures, managers in Trimo are aware that they require a great deal of management evaluation, so measures become more subjective, but that's the way it is, especially as these measures are exceedingly important to the company.

Key processes are derived from the corporate strategy, which is updated annually at the Strategic business conference, at which key factors are defined as follows: customer satisfaction, employee satisfaction, good business results and a positive attitude towards the environment. KPIs are used by top management to monitor organizational 
performance in key strategic areas, as defined by key processes in the company. There are 62 KPIs ( $c f$. Peljhan 2005 ) and 28 of them are included in BSC. In Trimo, managers consider KPIs once a week at their Management board meeting. In diagnostic control, managers use a management-by-exception approach when discussing the reports at the weekly Management board meetings. As the Quality Assurance Director (Trimo 2005c) says: "Reports contain explanations for KPIs variances and whether they present problems or not." Only problems (i.e. deviations) are discussed and appropriate actions taken. That the changes trigger revised action plans is reflected in the following Quality Assurance Director's statement (Trimo 2005c): "In the weekly meetings in which we discuss KPI for each organizational unit (sector) specific decisions are made about what actions we have to take in case of deviations."

Detailed reports are prepared by the respective departmental managers and are then communicated to top management in summaries of approximately one page, pointing out deviations that need special management attention. Low and middle managers responsible for the reported deviations prepare actions for improving minor deviations, while major deviations are considered by top management who adopt the necessary corrective measures to achieve short- and long-term goals weekly. According to KPIs trends, top management decides to take corrective measures if necessary, and then regularly control the effectiveness of these actions.

\subsection{Interactive Control Systems}

From the questionnaire's replies analysis and interviews with top managers (Trimo 2004a, 2004b; Trimo $2005 \mathrm{c}, \mathrm{d}, \mathrm{e}, \mathrm{f}, \mathrm{g}$ ), it was concluded that they use budgeting interactively. This conclusion is underlined with the following observations. Trimo's managers often use budgeting information as a means to question and debate their ongoing decisions and actions. The budgeting process is continuous - it demands regular and frequent attention from managers at all levels. There is a lot of interaction between top management and middle and low managers in the budgeting process. Managers use the budgeting process to discuss changes occurring in the company with their peers and subordinates (see also Abernethy \& Brownell 1999). In the early 1990s, they used the budgetary system as a diagnostic MCS. Here, the main goal of budget tracking was to ensure that previously established objectives were met. On the other hand, in recent years they have used budgets interactively with the main goal of forcing continued questioning and revisions of the assumptions upon which their plans are based. Furthermore, BSC also includes elements of an interactive control system for the development and implementation of strategic initiatives, which leads to the achievement of the strategic objectives. Trimo's BSC contains elements of an interactive control system in that it reinforces the learning organization concept by providing the possibility to test cause-and-effect relationships ( $c f$. Peljhan 2005).

Trimo's top management is accessible to every employee. They constantly communicate with the work teams and every employee can contribute to possible improvements by giving suggestions in writing, or orally, to their team leader or directly to the top management within the $\mathrm{CIP}^{3}$ program or key files ${ }^{4}$ programme. Members of a work team within the CIP program or key files program actively co-operate by giving suggestions for improvements. The suggestion that receives the majority support is defined as a project, with a project manager, members of the project team (members can be cross-functional depending on the nature of the project), project objectives and deadlines. The number of suggestions per employee within the CIP and key files represents one of the criteria for promotion. In this way, CIP and key files are important components of the interactive control system in Trimo. As we have already described in earlier chapters, managers in Trimo are actively included in the process of continuous improvement that is facilitated by flat organizational structure and team working with the common goal of continuous improvement for customers, employees, shareholders and other stakeholders.

\footnotetext{
${ }^{3} \mathrm{CIP}$ is the abbreviation for the Continuous improvement process, which was formally set as a programme characterising the constant struggle to improve Trimo's products and production technology.

${ }^{4}$ Key files are used in improvements in the area of business processes. They are facilitated by 28 TQM promoters, who are usually prospective young employees. Promoter motivates other employees in improving the processes. Each process improvement is monitored and evaluated through 'key file' with preset targets and savings estimations. The main difference between CIP and key files is that CIP projects are usually shorter and concern a narrower working area of the improvement proposer. The achieved results with regard to key files are monitored monthly by a TQM promoters' team and are presented quarterly at the Management board meeting.
} 
Managers achieved the concept of shared control that goes both bottom-up and top-down, involving all employees in CIP and key files projects. When dealing with problems and when improving processes, Trimo employees have to be able to express their opinions and say what they are going to do about the perceived problems. In particular, managers are very action-oriented. Their continuous purpose is to pass this focus downwards to all employees. This shatters the usual dichotomy between the thinkers and doers within the organization. As expressed by the Managing Director (Trimo 2005b), the all pervasive attitude always has to be "we are never good enough".

Recently, Trimo has focused intensively on systems for knowledge management, according to learning organization philosophy. Knowledge management is primarily seen as a way of taking advantage of the scale and scope of the accumulated experience generated within a company. Another key aspect is to diminish the importance of the individual and personal experience. The idea is that ideas and experiences developed in one project can be recycled and re-used with minimal adaptation in other projects. The premise is that experience can be codified and rationalized in a way that suits database storage and retrieval. Here, the most important approach is building competencies maps. We would like to emphasize that they are also rather innovative in this respect, as many companies are building knowledge maps, whereas Trimo focuses on all competencies, taking into account that knowledge is only one part of competencies. Knowledge is necessary, but not sufficient, especially when working in Trimo's organizational culture of innovative and task-oriented approach to performance management.

Simons' (1995b) framework emphasizes the relevance of the interactive use of MCS in fostering successful innovation, including successful product innovation. Simons $(1991,1995 \mathrm{~b})$ suggests that the interactive use of MCS influences the impact of innovation on organizational performance. According to Simons (1995b, p. 102), "by choosing to use a control system interactively, top managers signal their preferences for search" and, in particular, the top managers' aim in using interactive controls is "to focus attention (of the members of the organization) on strategic uncertainties" (Simons 1995b, p. 100). Following Simons' framework, it can be expected that by orientating the contents of the product innovation initiatives, interactive control systems "harness the creativity that often leads to new products" (Simons 1995a, p. 86), contribute to the adequacy of the innovation initiatives that are pursued and help ensure the success of innovation initiatives, so that they have beneficial consequences on performance. Based on observations and interviews, it is concluded that the relationship between the level of innovation and organizational performance in Trimo enhanced as focus, integration and fine-tuning, are obtained through the interactive use of MCS. Bisbe and Otley (2004) state that when a company is undergoing little or no product innovation, this potential enhancement is likely to be limited or insignificant, since the need for focus, integration and fine-tuning can be expected to be less compelling. These arguments are consistent with propositions stating that interactive control systems are particularly needed in contexts where it is crucial that innovation is effective (Simons 1995a) such as under build, product differentiation and prospector and entrepreneurial strategies (Langfield-Smith 1997), all describing the elements of Trimo strategies (Peljhan 2007).

The influence of the interactive use of MCS on the effect of innovation on performance in Trimo is achieved through different mechanisms. First, interactive MCS provide focus and therefore indicate where to concentrate innovative efforts so that they are consistent with organization-wide strategic orientation ( $c f$. Van de Ven 1986). In Simons' terms, interactive control systems are used by top managers "to communicate where to look" (Simons 1995b, p. 93). This is ordinarily done within the strategic domain, defined by beliefs and boundary systems, even though focusing attention and learning on strategic uncertainties (Simons 1995b) may occasionally lead to reframing the strategic domain. Second, interactive MCS provide an agenda and a forum for the regular face-to-face dialogue and debate needed, helping "to collectively make sense of changing circumstances" (Simons 1995b, $\mathrm{p}$. 218). Finally, interactive control systems provide a lever to permanently fine-tune analyses and actions, contributing to making the right changes and altering product innovation initiatives as competitive markets change. Employees use the interactive control system to "inform them of changing patterns and (to) allow them to respond with new action plans" (Simons 1995b, p. 98).

\subsection{Beliefs And Boundary Systems}

When discussing beliefs and boundary systems issues with Trimo's top and middle managers, it was found that beliefs and boundary systems in Trimo can be presented together as they are so inter-connected that it is almost 
impossible to draw a line between them. Managers use beliefs systems to imbue the workforce with a set of "company values" so that these values will underpin organizational activity ( $c f$. Simons 1995b, 2000). The changed top management since 1992 has had a big impact on strategic activity within the company, as it changed the "climate for doing things". Our informants referred to this in the context of an increase in the diversity of ideas and initiatives that were "deemed acceptable" and, thereby, "able to see the light of day". We found out that the focus on "value-adding" results in "positive rivalry among teams because each one is trying to come up with a better idea".

With regard to beliefs systems, the Managing Director's characteristics of a transformational leader were essential during the period of strategic change from a defender to a prospector strategy (Peljhan 2007). She, as a transformational leader, (and of course by the help of whole top management team) managed to alter the existing structure of the early 1990s and influenced people to buy into a new vision and new possibilities. Based on observations, it is concluded that her primary focus since 1992, when she took over the managing director position, has been to create a change process that continually causes people within the organisation to learn and grow. She builds shared vision and goals and implements them through teamwork and a high level of commitment.

From the general description of the company and the historical review of its way to business excellence ( $c f$. Peljhan 2005; Tekavčič \& Peljhan 2004), we state that a clear company mission and business strategy, together with extensive R\&D efforts, have become the basis for Trimo's success. Trimo's management believed that in order to achieve this, the company mission and business strategies had to be communicated to every employee in advance, to set an appropriate basis for understanding why changes are important. In Trimo, top management uses special questionnaires to check understanding of the mission, vision, values and the entire organizational culture among employees. The results for 2002 show that 98 per cent of employees know the essential company values (Trimo 2005a).

In order for a new business philosophy and related practices to be embedded into the decisions and actions of every employee, the philosophy of Trimo's management was written down in "Trimo Standards", comprising basic principles that all employees are expected to follow. These standards are a prime example of the combination of beliefs and boundary control systems in Trimo. They point at company values, as well as represent simple rules of "allowed" behavior. These standards are communicated continually to all employees at annual workshops and are also an important part of the training programmes for newly hired employees. Standards are underpinned by four sets of core Trimo values (see: Figure 2).

Figure 2: Trimo's core values

PEOPLE: Employees are the key strength of Trimo. Company's power depends on the management and all employees. Values are team work, goal orientation, creativeness, innovativeness and individual talents.

CUSTOMERS: Enthusiastic and satisfied customer is measure of our success. We develop and improve original and complete product and service solutions for our customers.

VALUE ADDED: Profit and value added growth and cash flow available enable quicker company development.

ENVIRONMENT: We take care of well-organised factory and are friendly to our environment. All employees' health is the value accomplished by the healthy way of living.

Source: Trimo 2002. 
In Trimo, core values are outlined for the company as a whole, as well as for the individual employee, as the description of "Trimo Employee", as a value-driven code of business conduct (see: Figure 3). In Trimo, every employee is expected to know the mission, vision, basic goals and organizational culture of the company and must help to implement them. According to Trimo Standards, only those people who are responsible, loyal to the company and display self-initiative and creativity, will be able to carry out the business strategy. The latter is also the framework that determines the "Trimo Employee". According to observations, it is concluded that it is not necessary for employees to know the various elements of the "Trimo Employee" by heart, but they have to work and live in accordance with them. Moreover, the important part of boundary systems are also the "Ten basic rules for CIP projects" (cf. Zupan 2000)

Figure 3: Trimo Employee

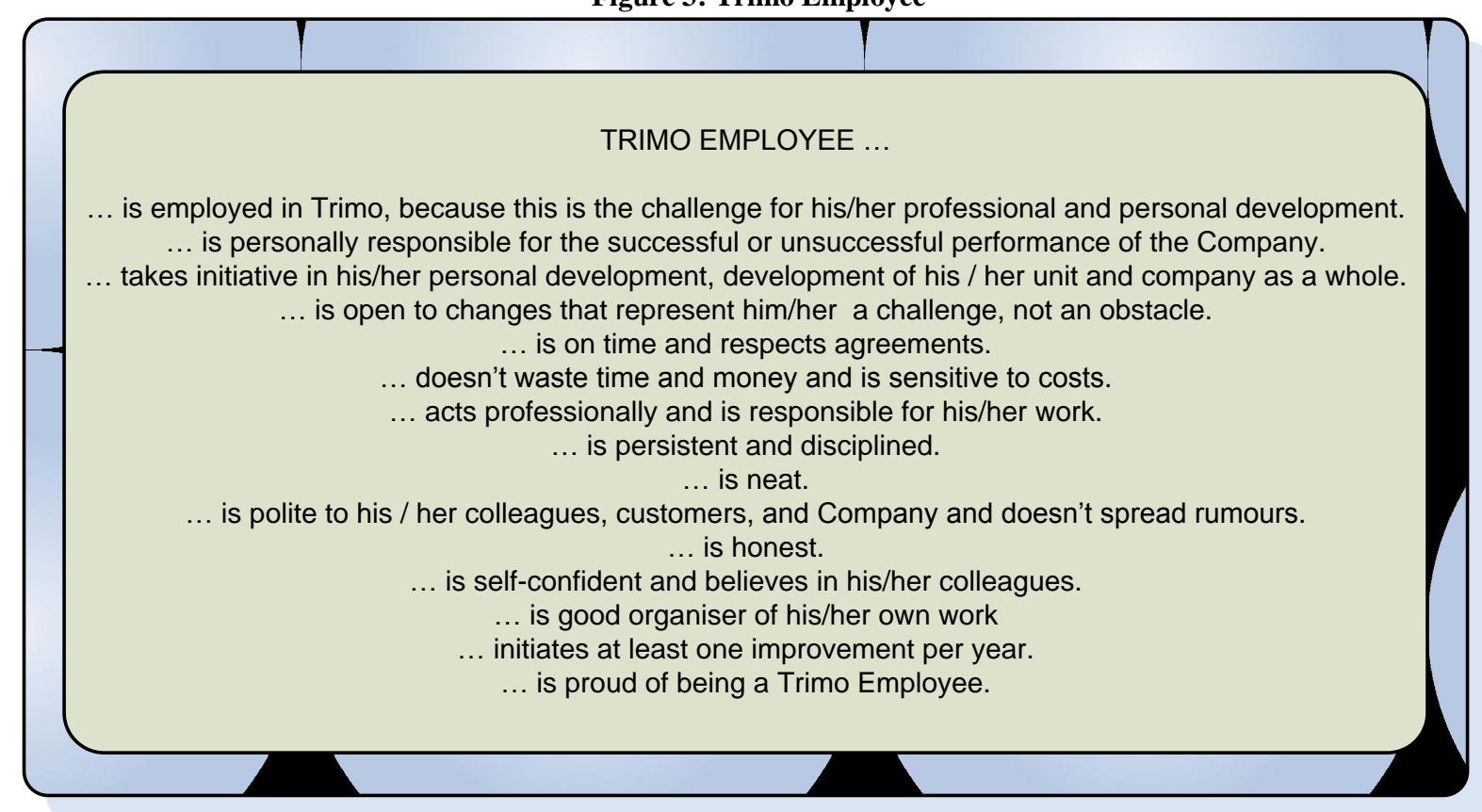

Source: Trimo 2005b.

The fulfillment of the discussed Trimo behavioral standards has an impact on employees' rewards, based on the supervisor's evaluation of an employee's behavior, according to these standards. This ensures that the most eager and successful employees advance vertically as well as horizontally and aims to foster the belief among employees that everyone is responsible for himself/herself, for the company and consequently for co-workers. All collectively contribute to achieving the same common goal. An important stone in implementing Trimo's way of doing things was also the fact that employees accepted it because they believed in it.

The description of organizational culture in Trimo and even more so, the intangible social and behavioral aspects of Trimo's culture, also represent the form of beliefs and boundary systems. Organizational culture in Trimo presents a very interesting mix of task-oriented performance-driven culture and an innovative culture. This is a real demonstration of control-flexibility tension in corporate values. In the company, there is a very strong focus on outputs and the delivery of assignments on time. This focus on the task is typically viewed as strength, since it contributes to make Trimo known as a reliable and trustworthy business partner that delivers what is promised. The company is well-known for its capacity to deliver on time. This is the outcome of the amount of resources in the company making it possible to put in extra people if needed, but perhaps even more important, is a broadly shared mentality on the significance of delivery on time. The company has a strong "delivery culture". At the same time, much appreciated values are creativeness, innovativeness and capabilities development. Trimo facilitates these 
values with programs such as CIP and key files. This mix of task/performance -oriented innovation culture works because of the Trimo's managers' leadership style, which facilitates employees' belief in Trimo's values.

With regard to boundary systems in Trimo, we should mention the process of strategy formulation. This is, in itself, a kind of boundary system controlling the courses of action in formulating strategies and keeping functional strategies within the borders of a business strategy. Moreover, the process of choosing new products to be developed and produced (see: Peljhan 2005), also corresponds to boundary control systems, as it directs, motivates and inspires appropriate innovative behavior of employees with regard to Trimo's strategic guidelines.

Finally, Trimo's BSC also contains elements of a beliefs and boundary control system in that it evolves from the vision, mission and strategic goals of the organization. Its four perspective framework depicts limits in the organization, as it encourages employees to focus their attention on the key aspects of the business. If we refer back to the role of "communication of strategy" inherent in the BSC implementation process, we recognize it is a tool which could be used for the dispersion of the core values of the company. Using the BSC in this way ensures that employees are aware of the mission of the organisation, of its main strategic goals and, more importantly, of the role that they have to play in their achievement. This facilitates the adherence to the core values outlined, as long as they are well understood by the employees.

\section{DISCUSSION}

In this section, we discuss the major findings important for further refinement of the existing theory. With regard to diagnostic control systems in Trimo, administrative controls are used across multiple levels of the company to secure strategy implementation. Given the claims about the power of performance indicators to influence behavior (e.g. Kaplan \& Norton 1996; Otley 1999), it is appropriate to begin by discussing the effects of Trimo's performance measurement system. Top management's use of KPIs, as interactive controls, has helped to guide strategic activity within Trimo. BSC is used for diagnostic control, monitoring financial and non-financial performance measures, as well as for an interactive way of management control. Results indicate that the company operates in a very uncertain and complex environment, where balanced monitoring of financial and non-financial performance measures seems appropriate and useful.

Trimo established 28 focused measures as part of corporate BSC. The current problem with Trimo's BSC is that it does not allow for real-time presentation of all information. This problem will be overcome with the implementation of the new ERP system. At the moment, top managers are "overflowing" with too many measures, besides those in BSC and KPIs pertaining to particular key processes, reported in the information system they are using. For example, Aguilar (2004) argues that best-practice companies typically use 8 to 12 measures companywide. The main benefit of Trimo's performance measurement framework is that they use financial, people, customer, and operations measures. Managers receive the specific information they need in electronic form in a concise format. If they require more information about a particular measure (e.g. sales growth by product, area, etc.), they can simply drill down for greater detail. Measures agreed upon are included in each sector's weekly report, prepared by the individual sector manager and his/her staff. These measures help managers to take actions that are directly related to achieving the company's strategic guidelines. Such measures also show top management where the best results are coming from, so that success can be recognised and rewarded.

Interactive control systems in Trimo are an instrument for organizational learning. By monitoring key strategic uncertainties and discussing them internally, especially among managers, the company enhances learning and refines its strategic options. Management's vision for the future gives rise to specific strategic uncertainties that relate especially to changes in technology, customers' preferences, competitor actions and raw materials prices. The discussion about how to react to potential strategic uncertainties forces organizational learning. In Trimo's use of integrative MCS, a very important part is played by middle managers and TQM promoters having the liaison role of facilitating vertical and horizontal communication.

In Trimo, they designed MCS which encourage increased interaction between top management and subordinates and thus facilitates increased information flows. This is also argued by Galbraith (1973). In Trimo, 
interactive use of budgeting provides a vehicle for top management to reveal its values and preferences to other employees. It enables the interchange of information concerning the opportunities, threats, strengths and weaknesses that exist in the internal and external environment. Interactive use of budgeting provides a means of debating how to respond to changes in environmental and operating conditions. That is also shown by Simons (1991). In Trimo, budgets serve as a "catalyst for debate" and thus help participants reach a compromise, rather than providing the "answer" (see also: Macintosh 1994). Budget variance information, for example, is used as a means of learning more about the possible alternatives and their consequences.

In this way, budgets play a proactive role in facilitating the effective implementation of possible strategic changes in the case of adapting to changes in an internal and external environment. This interactive use of budgeting corresponds to Shields' (1997) view. What is more, the interactive use of budgets, with its focus on dialogue, communication and learning, between top management and subordinates, as well as among managers at the same level, is consistent with the operation of cross-functional liaison groups as discussed in Abernethy and Brownell (1999). Indeed, it can be seen as an integrative liaison device that breaks down the functional and hierarchical barriers inhibiting information flows.

Three conclusions about Trimo's interactive control systems are drawn. First, these systems shape the rich bottom-up process of emergence of patterns of action in Trimo as a high innovative company through processes of CIP and key files. Managers and TQM promoters provide direction by signaling preferences for search, indicating those acceptable courses of action that are consistent with the overall business strategy and providing the basis for selecting those initiatives that maximize the impact on performance. This also corresponds to Bisbe and Otley's (2004) and Simons' (1995b, 2000) findings.

Second, interactive control systems facilitate the engagement of employees in regular, face-to-face dialogue and debate that is required for dealing with the non-routine, under-identified multi-disciplinary problems entailed especially in developing new products (see also Burns \& Stalker 1961; Chapman 1998; Chenhall \& Morris 1986; Galbraith 1973; Miles \& Snow 1978; Miller et al. 1988; Thompson 1967; Tidd et al. 1997). The consultation, collaboration, multi-faceted generation and evaluation of alternatives and integrated problem-solving that result from an interactive use of MCS enlightens decisions on process efficiency and product effectiveness, eventually improving the impact of innovation on performance (Chenhall \& Morris 1995; Verona 1999).

Finally, interactive control systems provide a lever to fine-tune and alter strategy as competitive markets change. As Trimo is becoming more and more innovative, the need for adjustments in strategy and strategy implementation will be even more frequent and the relevance of making the right changes will increase (Chapman 1997, 1998). A pattern of permanent, regular attention to strategic uncertainties is a defining feature of Trimo's interactive control systems.

To summarize, research findings support Simons' (1995b) assertion that successful innovators use formal MCS interactively. Also, we found that the relationship between an interactive use of MCS and product innovation may vary with the level of innovation. In the early 1990s, Trimo was a low-innovative company. When they began to pursue interactive use of formal MCS (e.g. BSC, interactive use of budgeting, CIP, key files), they evidenced stimulated creativity and product innovation. However, the interactive use of formal MCS does not appear to be the only stimulator of creativity and innovation in recent years, when Trimo became a high-innovative company. During these years, creativity, the generation of ideas and launching of new initiatives was encouraged through different, formal and informal systems (Bisbe \& Otley 2004; Chenhall \& Morris 1995; Clark \& Fujimoto 1991; Roussel et al. 1991). The most influential informal control systems in Trimo are the managers' leadership style and the organizational culture. However, an issue to be considered by Trimo's management in the future should be to focus on the quality and not the quantity of innovation initiatives. Today, they are doing a great job in this context.

Beliefs and boundary systems in Trimo comprise a set of procedures which top management uses to prescribe and proscribe the company's overall strategic purpose or vision (see also: Bartlett \& Ghoshal 1993). Trimo's beliefs system corresponds to Simons' (1995b, p. 34) definition that this system is "the explicit set of organizational definitions that senior managers communicate formally and reinforce systematically to provide basic 
values, purpose, and direction for the organization". Additionally, in Trimo, the major part of communication goes through informal channels, especially with the influence of the management (leadership) style and organizational culture. Boundary systems, on the other hand, "delineate the acceptable domain of strategic activity for organizational participants" (Simons 1995b, p. 39). Both systems are established and reinforced through a set of communication channels, including formal mission statements, credos, e-mails, and meetings. Boundary systems are also created and communicated through mechanisms such as strategic planning systems, (un)written codes of conduct - reflected in the organizational culture - and formal rules and procedures. Beliefs and boundary systems in Trimo are used to facilitate people's comprehension of the overall organizational purpose and values.

In Trimo, the belief and boundary systems ware altered in the 1990s for creating the impetus for a new strategic agenda set in 1992/1993 and updated in subsequent years. This corresponds well with arguments advanced by Argyris (1985) and Simons (1995b) positing that before momentum can be created in a new direction, old behaviors have to be unlearned, and the way that unlearning is initiated is through the refined or changed belief and boundary systems. In Trimo, these systems have been communicated as follows:

- $\quad$ Through written statements, followed by face-to-face presentations and discussions at an annual Strategic Conference.

- $\quad$ At annual education days for all employees.

- $\quad$ Continuously presented in the Trimotim magazine.

In interpreting the values and explaining their role, these systems help to define where to allocate attention and resources. Social controls as an important part of beliefs and boundary systems in Trimo were formally implemented in 2002 when "standardizing" behavioral expectations in 'Trimo Standards' for goal alignment, thus securing a more uniform and rapid implementation of Trimo values.

This study confirms the findings of several other studies, which have found greater use of beliefs systems among companies, as they seek to maintain organizational coherence in the face of increasing complexity and uncertainty (Bartlett \& Ghoshal 1993; Simons 1995b). The way that Trimo has operated its value system also supports prior suggestions (Simons 1995b). First, strategic guidelines have been implemented by a range of formal and informal communication channels, particularly mission statements, strategic conferences and all-company educational "strategy days" etc. Second, beliefs systems have been deployed to engineer organizational change and overcome organizational inertia (Trice \& Beyer, 1991), which Simons (1994) argues is a crucial role of beliefs systems. The results indicate that beliefs and boundary systems, through their impact on Trimo's strategic climate, strike at the very heart of strategy making. They influence which ideas and initiatives managers will champion and, more importantly, problems of information asymmetry, which are discarded at the outset. Similar conclusions were reached by Dutton and Ashford (1997) and Marginson (2002), the former in a US company and the latter in a UK company.

\section{CONCLUSION}

Simons' levers of control framework $(1990,1991,1995 \mathrm{~b}, 2000)$ focuses on the tensions between the organizational need for innovation and the organizational need for the achievement of pre-established objectives, and points out the consequent tensions among components of MCS that need to be managed in order to successfully deal with these organizational needs. The paper has looked at tensions and balances between different styles of the use of formal MCS (e.g. diagnostic, interactive, beliefs, boundary), as well as among types of control systems (e.g. formal vs. informal) to enhance understanding of the broader framework of overall control packages. The study's contribution is that it incorporates a wider range of controls, including informal (i.e. social) mechanisms, to provide a more comprehensive analysis, as opposed to the majority of prior contingency studies focusing on a more limited range of controls. As such, the results of the majority of prior studies were not representative of the breadth of controls used by a company and do not capture the interactive effects of the broad range of controls. In this respect, this paper contributes to the literature in terms of examination of the broader components of MCS than was previously done. The future theory refinements have to consider informal controls (e.g. organizational culture, 
leadership style) as being equally important as formal controls (e.g. accounting systems, BSC, profit plans, internal controls).

\section{REFERENCES}

1. Abernethy, MA \& Brownell, P 1999, 'The role of budgets in organizations facing strategic change: an exploratory study', Accounting, Organizations and Society, vol. 24, no. 3, pp. 189-204.

2. Aguilar, O 2004, 'How Strategic Performance Management Is Helping Companies Create Business Value', in JB Edwards (ed.), Emerging Practices in Cost Management, WG\&L/RIA Group, Valhalla, pp. B2-1 B2-5.

3. Anthony, R \& Govindarajan, V 2001, Management Control Systems, $10^{\text {th }}$ ed., McGraw-Hill Irwin, Boston.

4. Atkinson, AA \& Shaffir, W 1998, 'Standards for Field Research in Management Accounting', Journal of Management Accounting Research, vol. 10, pp. 41-68.

5. Bartlett, CA \& Ghoshal, S 1993, 'Beyond the reform: toward a managerial theory of the firm', Strategic Management Journal, vol. 14, no. 8, pp. 23-46.

6. Bhimani, A \& Langfield-Smith, K 2007, 'Structure, formality and the importance of financial and nonfinancial information in strategy development and implementation', Management Accounting Research, vol. 18 , no. 1 , pp. 3-31.

7. Bisbe, J \& Otley, D 2004, 'The effects of the interactive use of management control systems on product innovation', Accounting, Organizations and Society, vol. 29, no. 8, pp. 709-737.

8. Burns, T \& Stalker, GM 1961, The Management of Innovation, Tavistock Publications, London.

9. Chapman, CS 1997, 'Reflections on a contingent view of accounting', Accounting, Organizations and Society, vol. 22, no. 2, pp. 189-205.

10. Chapman, CS 1998, 'Accountants in organizational networks', Accounting, Organizations and Society, vol. 23, no. 8, pp. 737-766.

11. Chenhall, RH 2003, 'Management control systems design within its organizational context: findings from contingency-based research and directions for the future', Accounting, Organizations and Society, vol. 28, no. 2-3, pp. 127-168.

12. Chenhall, RH \& Morris, D 1986, 'The Impact of Structure, Environment, and Interdependence on the Perceived Usefulness of Management Accounting Systems', The Accounting Review, vol. 61, no. 1, pp. 1635.

13. Chenhall, RH \& Morris, D 1995, 'Organic decision and communication processes and management accounting systems in entrepreneurial and conservative business organizations', Omega: International Journal of Management Science, vol. 23, no. 5, pp. 485-497.

14. Clark, KB. \& Fujimoto, T 1991, Product development performance: Strategy, organization, and management in the world auto industry, Harvard Business School Press, Boston.

15. Dutton, JE \& Ashford, SJ 1997, 'Reading the wind: how middle managers assess the context for selling issues to top managers', Strategic Management Journal, vol. 18, no. 5, pp. 407-425.

16. Eden, C \& Huxham, C 2002, 'Action research', in D Partington (ed.), Essential Skills for Management Research, Sage Publications, London, pp. 254-272.

17. Eisenhardt, KM 1989, 'Building Theories from Case Study Research', The Academy of Management Review, vol. 14, no. 4, pp. 532-550.

18. Flamholtz, EG, Das, TK \& Tsui, A 1985, 'Toward an integrative framework of organizational control', Accounting, Organizations and Society, vol. 10, no. 1, pp. 35-50.

19. Galbraith, JR 1973, Designing Complex Organizations, Addison-Wesley Publishing Company, Reading.

20. Ittner, CD \& Larcker, DF 2002, Empirical managerial accounting research: are we just describing management consulting practice, The European Accounting Review, vol. 11, no. 4, pp. 787-794.

21. Kaplan, RS \& Norton, DP 1996, The Balanced Scorecard - Translating Strategy into Action, Harvard Business School Press, Boston.

22. Kaplan, RS \& Norton, DP 2001, The Strategy Focused Organization: How Balanced Scorecard Companies Thrive in the New Business Environment. Harvard Business School Press, Boston.

23. Kranjec, S 2003, 'Trimo želi postati vodilni v Evropi [Trimo wants to be the European leader]', Finance (Priloga), 28 October, p. 20. 
24. Langfield-Smith, K 1997, 'Management control systems and strategy: a critical review', Accounting, Organizations and Society, vol. 22, no. 2, pp. 207-232.

25. Macintosh, NB 1994, Management accounting and control systems: an organizational and behavioural approach, John Wiley \& Sons, Chichester.

26. Marginson, DEW 2002, 'Management control systems and their effects on strategy formation at middlemanagement levels: Evidence from a U.K. organization', Strategic Management Journal, vol. 23, no. 11, pp. 1019-1031.

27. Merchant, KA 1985, Control in Business Organisations, Pitman, Boston.

28. Miles, RE \& Snow, CC 1978, Organizational Strategy, Structure and Process, McGraw-Hill Book Company, New York.

29. Miller, D, Dröge, C \& Toulouse, J 1988, 'Strategic process and content as mediators between organizational context and structure', Academy of Management Journal, vol. 31, no. 3, pp. 544-569.

30. Noda, T \& Bower, JL, 'Strategy making as iterated processes of resource allocation', Strategic Management Journal, vol. 17, no. 7, pp.159-192.

31. Otley, DT 1980, 'The contingency theory of management accounting: achievement and prognosis', Accounting, Organizations and Society, vol. 5, no. 4, pp. 413-428.

32. Otley, DT 1999, 'Performance management: A framework for management control systems research', Management Accounting Research, vol. 10, pp. 363-382.

33. Otley, DT 2001, 'Extending the Boundaries of Management Accounting Research: Developing Systems for Performance Management', British Accounting Review, vol. 33, pp. 243-261.

34. Ouchi, WG 1980, 'Markets, Bureaucracies and Clans', Administrative Science Quarterly, vol. 25, no. 1, pp. 129-141.

35. Peljhan, D 2007, The role of management control systems in strategy implementation: The case of a Slovenian company. Economic and Business Review, 9 (3): 257-280.

36. Peljhan, D 2005, Management Control Systems for Organisational Performance Management: A Case of a Slovenian Company, PhD Thesis, University of Ljubljana, Faculty of Economics, Ljubljana.

37. Roussel, PA, Saad, KN \& Erickson, TJ 1991, Third Generation R\&D: Managing the Link to Corporate Strategy, Harvard Business School Press, Boston.

38. Shields, MD 1997, 'Research in management accounting by North Americans in the 1990s', Journal of Management Accounting Research, vol. 9, pp. 3-62.

39. Simons, R 1987, 'Planning, Control, and Uncertainty: A Process View', in WJ Bruns, Jr. \& RS. Kaplan (eds), Accounting and Management: Field Study Perspectives. Harvard Business School Press, Boston, pp. 339-362.

40. Simons, R 1990, 'The role of management control systems in creating competitive advantage: new perspectives', Accounting, Organizations and Society, vol. 15, no. 1-2, pp. 127-143.

41. Simons, R 1991, 'Strategic orientation and top management attention to control systems', Strategic Management Journal, vol. 12, no. 1, pp. 49-62.

42. Simons, R 1994, 'How new top managers use control systems as levers of strategic renewal', Strategic Management Journal, vol. 15, no. 3, pp. 169-189.

43. Simons, R 1995a, 'Control in an Age of Empowerment', Harvard Business Review, vol. 73, no. 2, pp. 8088.

44. Simons, R 1995b, Levers of Control: How Managers Use Innovative Control Systems to Drive Strategic Renewal, Harvard Business School Press, Boston.

45. Simons, R 2000, Performance Measurement and Control Systems for Implementing Strategy, Prentice Hall, Upper Saddle River.

46. Šević, Ž 2005, 'A Puzzle of Emerging Markets: A Systemic 'Surprisingability', Managerial Finance, vol. 31, no. 12, pp. 1-10.

47. Tekavčič, M \& Peljhan, D 2004, 'Achieving business excellence prize: The case of Trimo Trebnje d.d.', International business \& economics research journal, vol. 3, no. 10, pp. 49-63.

48. Thompson, JD 1967, Organizations in Action: Social Science Bases of Administrative Theory. McGrawHill Book Company, New York.

49. Tidd, J, Bessant, J \& Pavitt, K 1997, Managing Innovation: Integrating Technological, Market and Organisational Change. John Wiley \& Sons, Chichester. 
50. Trice, HM \& Beyer, JM 1991, 'Cultural leadership in organizations', Organization Science, vol. 2, no. 2, pp. 149-169.

51. Trimo 2002, Business Excellence Report.

52. Trimo 2004a, Semi-formal interviews with Managing Director and her presentation at the 2004 Strategic Conference, Bled, 6-7 February 2004.

53. Trimo 2004b, Interview with Manufacturing Director, March 2004.

54. Trimo 2005a, Trimo Dialogue - appraisal questionnaire.

55. Trimo 2005b, Managing Director's presentation at the 2005 Strategic Conference, Bled, 4-5 February 2005.

56. Trimo 2005c, Interview with Quality Assurance Director, 7 June 2005.

57. Trimo 2005d, Interview with Quality Coordinator, 9 June 2005.

58. Trimo 2005e, Interview with Managing Director, 28 June 2005.

59. Trimo 2005f, Results of the questionnaire sent to top managers, March-May 2005.

60. Trimo 2005g, Interviews with HR Director, 7 and 9 June 2005.

61. Trimo 2005h, Business manual, $9^{\text {th }}$ ed. Trebnje: Trimo.

62. URL: http://www.trimo.si/, 4 March 2005.

63. Van de Ven, AH 1986, 'Central problems in the management of innovation', Management Science, vol. 32, no. 5, pp. 590-607.

64. Verona, G 1999, 'A resource-based view of product development', The Academy of Management Review, vol. 24, no. 1, pp. 132-142.

65. Yin, RK 2003, Case study Research: Design and Methods, 3rd ed., Sage Publications, Thousand Oaks.

66. Zupan, N 2000, 'Kako vključiti zaposlene v uresničevanje vizije podjetja: primer Trimo d.d. [How to include employees in company's vision implementation: The case of Trimo d.d.]', in J Prašnikar (ed.), Internacionalizacija slovenskega podjetja, Finance, Ljubljana, pp. 197- 223. 